\title{
A CASE OF A SPASM OF THE CENTRAL ARTERY OF THE RETINA
}

\author{
BY \\ Dr. NASR Farid Bey \\ CAIRO
}

IN old times one believed that embolism of the central artery of the retina was always mixed with a spasm of the same artery.

Now new light has been thrown on this subject by Abadie and subsequently by Redslob. Abadie thinks that embolism of this artery is very rare. He himself has seen only two or three cases of it. On the contrary, spasm of the central artery is very frequent.

The ophthalmoscopic picture of embolism is the expression of changes which set in when the arterial supply of blood is cut off from the retina. Such occlusion may be produced too by a spasm of the central artery of the retina with this difference, that the resulting blindness in embolism comes on suddenly, while in spasm it comes on in crisis. In embolism the degeneration of the vessels in the macular region is more extensive; in spasm there are intermittences in the course of the blood flow. The reaction of the pupil is lost in embolism because the course of the sympathetic nerve is cut, but in spasm the reaction is still present.

The aetiological factors of embolism are usually heart or kidney lesions, but in spasm causal factors are reactions of sympathetic origin. Individuals, subject to angina pectoris are disposed to develop spasm of the central artery of the retina ; infectious diseases have the same effect.

The patient, a physician aged 42 years, presented himself to me on March 31, 1928, complaining that for the past year he had not seen well with the right eye.

The following history was obtained:-In 1919 the patient had frequent attacks of angina pectoris; these continued for six years and then began to diminish. There were no signs of arterial degeneration; the blood pressure was 130-90. One year before presenting himself to me the patient had a severe attack of typhoid fever and had to stay in hospital for 5 months; the typhoid was complicated by an inflammation of the gall bladder. During the last 2 weeks of the illness, there developed symptoms in the right eye which were diagnosed at that time as being due to an embolism of the central artery of the retina. In July, 1922, my colleague Dr. Sobhi had seen the patient and stated that " he sees with the right cye only hand movements." Dr. Sobhi advised a paracentesis but the physician refused it, fearing infection. 


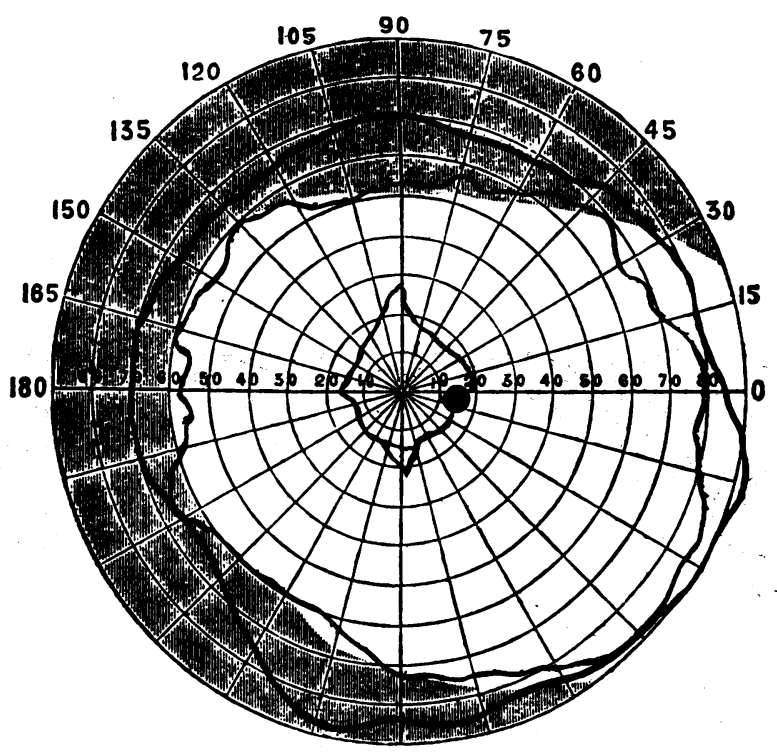

Field of March 31, 1928.

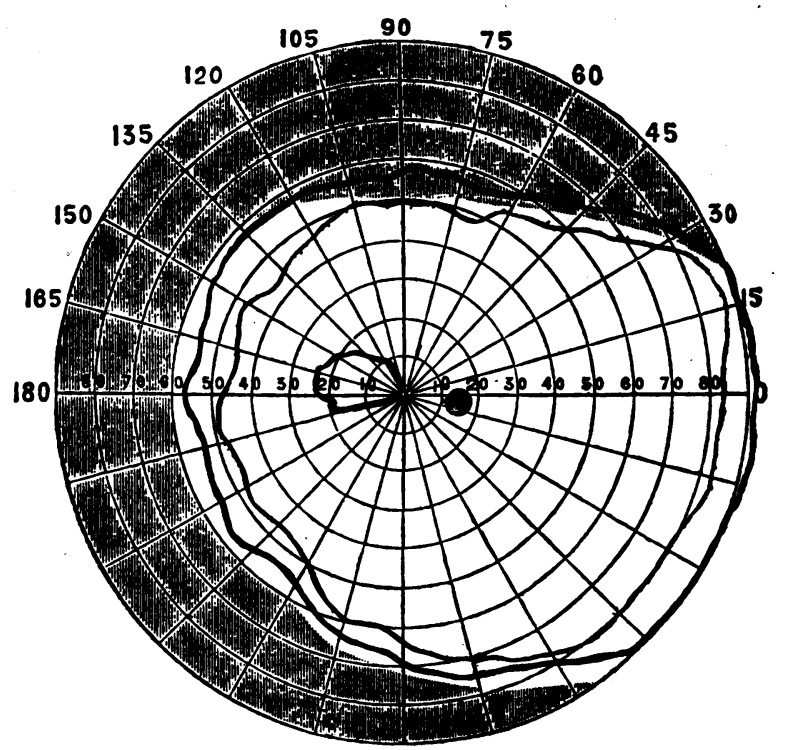

Field of July 17, 1929. 
Present state: The pupil of the right eye is slow in reaction. Vision :

$$
\begin{aligned}
& \text { R.E. }-1.0 \text { D.sph. } 0-0.5 \text { D.cyl. } 10^{\circ}=6 / 24 \text {. } \\
& \text { L.E. }-0.5 \text { D.sph. }=6 / 6 \text { partly. }
\end{aligned}
$$

The field of vision is normal in both eyes; there is a scotoma in the right eye the reason for which is disclosed by fundus examination. Extreme arterial anaemia of the retina is found.

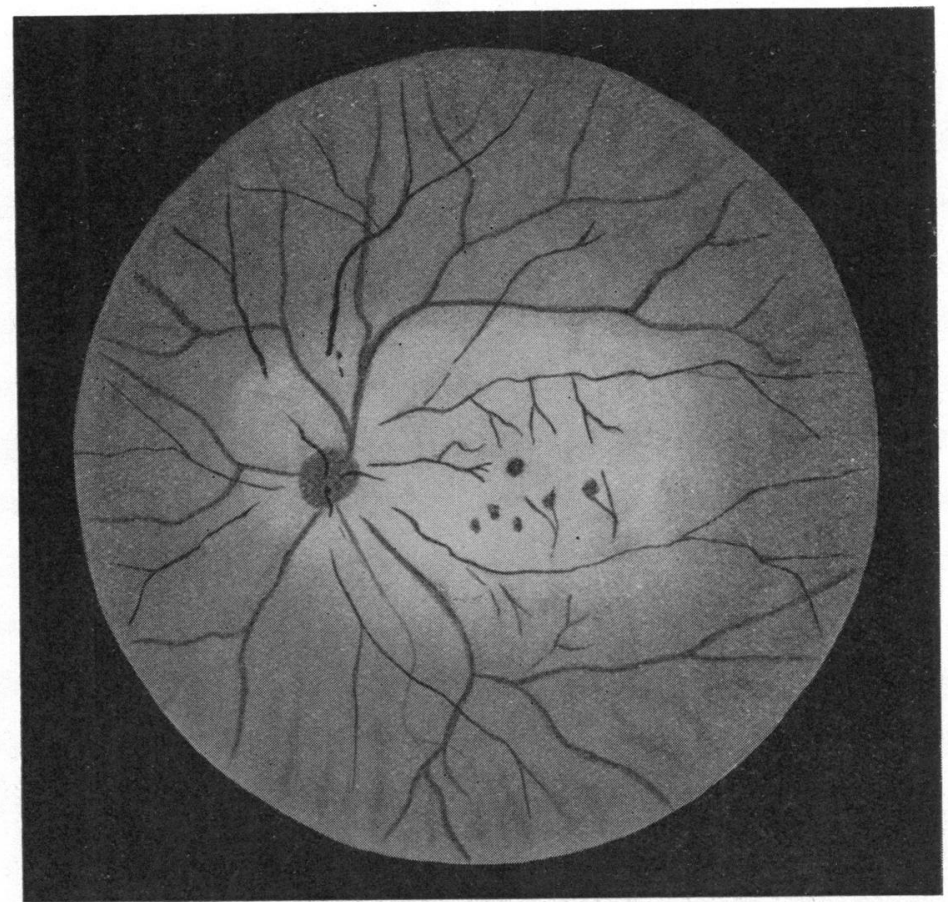

The larger arteries are reduced to thin filaments; the smaller ones are invisible. On the other hand, the veins are not markedly contracted except upon the papilla itself; the latter appears paler and the retina is opaque and milky and most markedly so in the vicinity of the papilla and macula. Owing to this opacity, the outlines of the papilla are obscured but on the other hand fine ramifications of the retinal vessels, such as ordinarily are not visible with the ophthalmoscope, are seen in the vicinity of the fovea where they stand out clearly upon the white background. At the centre of the fovea a vivid red spot stands out of the cloudy white background (see illustration). 
On July 17, 1929, I saw the patient again. Vision was the same, as was the field of vision; the central scotoma was slightly smaller; the fundus showed atrophy of the retina. Arteries were filamentous. Veins were full. The disc was atrophic, and there was choroidal atrophy surrounding the macula lutea.

The patient died suddenly in August, 1929, in a severe attack of angina pectoris. Unfortunately he was buried the same day, and I was therefore unable to obtain the eye for pathological examination.

\section{BIBLIOGRAPHY}

Abadie.-La Clin. Ophtal., Apr 1, 1925.

Redslob.-Rev. d'Oto-Neuro d'Ocul., July, 1925.

Halbertsma. - Un cas de spasme de l'artère centrale de la rétine. Ann.d'Ocul., September, 1926.

Hairi (Constantinople).-Le spasme de l'artère centrale de la rétine. Ann. d'Ocul., September, 1926.

Fuchs. - Textbook of Ophthalmology, p. 732, 1917.

\section{THE USE OF THE DIATHERMY CURRENT IN EYE DISEASES}

BY

PHILIP FIGDOR, M.B.

PHYSICIAN TO THE ELECTRO-THERAPEUTIC DEPARTMENT, ST. JOHN'S HOSPITAL, LEWISHAM, ETC.

Heat, in some crude form or other, has long been used for the relief of pain in any part of the body, including the eye. Heat is also used in treating disease, even without pain.

Crude heat or external heat, i.e., heat generated outside the body, must exert surprisingly little therapeutic effect when applied to the eye. The penetrative power is minute and the resultant hyperaemia is very superficial. The chief therapeutic objection, however, is that it is impossible to maintain the initial temperature, once the application is made.

A method of applying penetrating, persistent heat to the eye is possible by the use of the diathermy current. This current is a to-and-fro, alternating, current, which is made and broken; that is, enters and leaves the body, at a rate of from one million to three million times a second. The current that enters the body is sufficiently powerful to be dangerous, were it not for the amazingly high periodicity, which enables the current to leave the body again before it can kill person or tissues. (I may here interpolate that I am discussing medical diathermy, as distinguished from surgical 